\title{
Teoria e Prática nos estudos teatrais na Universidade
}

\author{
Patrice Pavis
}

1

ermitam-nos dizer isso logo de início e estamos felizes em fazê-lo: só na Universidade nós temos uma relação entre a teoria e a prática, mesmo que esta seja polêmica e não resolvida. Nas escolas privadas de atores, ou nas instituiçóes vocacionais (Conservatório $\mathrm{Na}$ cional, etc.), o treinamento é principalmente vocacional, e o teórico, que é sempre, de algum modo, suspeito, só é mencionado se ajudar a resolver algum problema prático. $\mathrm{Na}$ realidade, mesmo na universidade (francesa, americana ou australiana), a relação entre teoria e prática não é mais tão óbvia; na maior parte das vezes ela é desafiada e questionada pela evolução da sociedade e de nossas idéias sobre os estudos do teatro e/ou do espetáculo. Mas na educação de terceiro grau, profissionalizante, a tendência é promover um treinamento vocacional, oferecer oficinas aos atores, ensinar cenografia, economia ou direito, e preparar os estudantes para o seu ofício, permitindo que eles se envolvam com várias produções. Muito freqüentemente, os estudantes se matriculam na universidade pretendendo algo melhor: esperar, talvez, não por Godot, mas - e num certo sentido é a mesma coisa - pela possibilidade de ser aceito por uma escola de teatro prestigiada como o Con-

servatório Nacional ou uma Faculdade vocacional que os preparará para os diferentes mercados das artes cênicas. A crescente especializaçáo das diferentes técnicas teatrais e ramos do conhecimento, a ansiedade dos estudantes e administradores com seus respectivos futuros, tudo isso leva a um treinamento vocacional è à especialização do conhecimento. Isto ocorre freqüentemente às custas de um modo de pensar global e abrangente, generalista e universal, que não teria outro modo de se expressar se fosse extinguido na universidade.

Eis porque nós temos que reinventar, mesmo que seja contra a corrente e através de truques, espaços de pensamento na Universidade, o que nos força a repensar a coabitação e a descontinuidade entre teoria e prática dentro da nossa amada "alma mater", para reavaliar o objeto dos estudos teatrais e as condiçóes da prática teatral. E, se nós estamos estudando espetáculos diversos e polimorfos, até para questionar a relevância da noção de teatro, o objeto dos estudos teatrais é a experiência teatral, que é, ao mesmo tempo, considerada do ponto de vista de sua produção (autor, ator, diretor, cenógrafo etc...) e de sua recepção (público, sociedade, teóricos), uma experiência que é ao mesmo tem-

Patrice Pavis é professor da Universidade de Paris 8.

Conferência proferida por Patrice Pavis, ent Meulbourne, Austrália, em 19 de julho de 1997. Publicada em Conference Proceedings, Monah University, 1998. Tradução de Luiz Fernando Ramos. 
po intelectual e emocional, somática e cinética. Nós "simplesmente" temos que estudar esse objeto com as ferramentas certas, para alcançá-lo como experiência estética e desdobrá-lo em quantas várias áreas forem necessárias. Nós devemos ser cuidadosos para não limitar, ou fechar os diferentes campos de abordagem, tanto de uma perspectiva teórica quanto prática. Mas não é suficiente definir o objeto e o campo dos estudos teatrais. Há também que entrar em acordo quanto a uma certa epistemologia e metodologia que permita estudar-se esse objeto que é efêmero (o espetáculo), complexo (o texto dramático) e invasivo (a instituição). Um objeto que está sempre em preparação (ensaios), em ebulição (o espetáculo concreto) ou em evolução (a recepção dos textos dramáticos e das produçōes espetaculares). Mais ainda, o programa de estudos teatrais, apesar de ser muito nacionalista e universal, tem que ser historicizado, tem que refletir o momento histórico quando é trabalhado. Portanto, não pode, de modo nenhum, ser estabelecido de forma absoluta, de uma vez e para sempre, mas, sim, ser estabelecido dentro de um certo contexto histórico, geográfico e cultural, onde o estudo é feito. Não será o mesmo em Melborne, Paris, Nova Yorque, Tóquio e Nova Deli. Deveria ser o mesmo e Saint-Dennis, Nanterre e Censier? Teoricamente sim, praticamente é uma outra história. Mais ainda, a demanda também muda: por um longo tempo os estudantes reivindicaram muito a prática, para contrabalançar teorias abstratas, através principalmente de pessoas já trabalhando na profissão, mas, agora, eles estão sempre solicitando educação complementar e continuada.
É por conta das constantes mudanças nas práticas teatrais e de nossas idéias sobre o mundo, que parece razoável revisar periodicamente (digamos dez anos, duas vezes o tempo que você precisa para esquecer alguém) o mapa epistemológico dos estudos teatrais. Meu próprio último chek up foi feito há dez anos, em 1988, em Sidney, quando Gay McAuley me convidou para falar sobre os estudos teatrais na França, para definir meu objeto do desejo, para mapear o incerto campo dos estudos teatrais ${ }^{1}$ e para confrontar diferentes ramos de conhecimento, já que a prática teatral está sempre se renovando. Isso foi, justamente, antes da onda interculturalista, antes da institucionalização, principalmente nos Estados Unidos, dos estudos teatrais e da etnocenologia de Pradier, em um tempo quando os departamentos estavam ainda se perguntando se eles deveriam chamar-se Departamentos de Drama ou de Teatro. Atualmente, eu não partiria mais da oposição bastante filológica e ocidental, entre texto e espetáculo, entre uma definição precisa de disciplinas relativas à literatura dramática e as práticas do espetáculo. Nós estamos agora, pelo menos no mundo anglo-saxão, no meio de uma onda intelectual que já atingiu a capital da Gaul. Desde que todos parecem ter percebido que o teatro trabalha emprestando de diferentes fontes culturais e desde que, eu mesmo, pude oferecer minha contribuição em Theatre at the Crossroads of Culture ${ }^{2}$ e em International Performance ${ }^{3}$ me sinto na obrigaçáo de contrapor, ou pelo menos questionar, essa fase intercultural (mesmo o prefixo inter parece ter perdido seu significado preciso), para re-centrar e re-orientar minha pesquisa sobre o que eu conheço melhor:

1 Patrice Pavis. "Études Théâtrales". In: Theorie Litteraire. Direção de M. Argenot. Besviere, D. Fokema, E. Kushner. Paris, PUF, 1989, p. 98-107.

2 Idem. Theatre at the Crossroads of Culture. Londres, Routledge, 1992.

3 Idem. Intercultural Performance Reader. Londres, Routledge, 1996 
a tradição universalista, racionalista e sócio-crítica, a episteme ocidental, o "campo" do teatro ocidental no sentido proposto por Bordieu. ${ }^{4}$ Não é que eu de repente senti a necessidade de voltar para a pátria européia e que eu fui tomado por um fundamentalismo das raízes ocidentais. Não, ao contrário, eu só sinto que a teoria deveria ser menos vaga, mais crítica e radical, e que deveria lidar melhor com as produçóes teatrais existentes na Europa, nos Estados Unidos, na América Latina e em todos os países em que ainda se escrevem textos e se fazem produçōes, como tem sido feito na Europa, nos últimos 25 séculos, com os textos e, por cem anos, com os espetáculos. Eu também notei, caindo em mim, que nós devemos nos apressar na solução de todos os problemas e questóes a resolver, antes que o teatro e a classe média, que sempre manifestou interesse por ele, desapareçam no processo social e econômico de privatização e globalização, antes que a ligação entre prática e teoria se torne invisível, antes que não haja mais uma arte teatral nem uma teoria determinada que reflita e repense o mundo.

Enquanto a ciência pura falhou em propor uma teoria universal de teatro, a "soft theory" (teoria das ciências humanas) não parece ter sido muito melhor sucedida. O modelo da ciência pura era a semiologia dos anos setenta que tentou, pelo menos em sua versão caricatural, transformar em signos qualquer texto e qualquer produção, o que fragmentava o continum cênico em pequenas unidades mínimas. ${ }^{5} \mathrm{Ou}$ tras "ciências" humanas repuseram a semiologia, tentando descrever rigorosamente o acontecimento teatral, por exemplo: a biologia, a psicologia e mais recentemente a antropologia.
Para cada período de mais ou menos 10 anos, encontra-se uma tendência principal de pesquisa e uma disciplina correspondente.

\section{- 1960-75 : dramaturgia.}

- 1975-85 : semiologia.

- 1985-90 : desconstrução; feminismo.

- 1990-97 : interculturalismo, etno-teatralidade.

A ciência da antropologia tornou-se, nos noventa, a disciplina líder para numerosos estudos e formas não europeus. Quando misturada com a biologia e tomada de empréstimo por artistas e brilhantes "bricouleurs" como Grotowski, Barba ou Schechner, produz-se uma antropologia teatral que descobre princípios universais e ciências ad hoc que se empenham principalmente em justificar e entender as produçōes de suas próprias práticas teatrais e parateatrais. Tais ciências não são radicalmente diferentes das teorias que manifestaram suas desconfianças quanto ao sentido e à racionalidade e seu relativismo pós-moderno: por exemplo, o assim chamado "pós-estruturalismo" que é, na verdade, somente o pos-modernismo explicado para crianças ${ }^{6}$, e aplicado ao estruturalismo pelos adeptos da caneta rápida e do pensamento rápido. O que é um jeito de dizer sobre o desconstrucionismo que depois de Saussure, estruturalismo e semiologia, tudo é possível. Por exemplo, a desconstrução de textos e cenas, especialmente se elas forem mal construídas. Uma militante feminista, estreitamente sectária, ou mesmo separatista ao ponto de suicidar-se por isso, busca freqüentemente "questionar, desconstruir, re-visar trabalhos escritos por homens no século 19 , que eram restritos a homens,

\footnotetext{
4 Pierre Bordieu. Les regles de l'art. Genese et structure du champ littéraire.

5 Ver Patrice Pavis, L'analiye des spectacles. Nathan, 1996, cap. I.

6 Para parafrasear o título do livro de Jean-François Lyotard.
} 
brancos, ocidentais, de classe média alta, heterossexuais, com temas de meia idade,e com quem as mulheres (objetos) dividiam todos esses atributos com exceção de um". ${ }^{7}$ Uma "soft theory" como essa - se eu posso dizê-lo, apenas acumula diferentes determinaçóes (gênero, sexo, pano de fundo étnico, raça, origem social, idade, preferência sexual) sem explicar porque a litania obrigatória de todos esses termos e a obsessiva acumulação dessas qualidades (ou ainda de seus efeitos) produz o que se pode chamar de obras primas. Mas sugere que tais maus assuntos estão desqualificados para falar em seu nome e propor qualquer explicaçáo sobre o trabalho analisado, desde que se sabe de antemão que tipo de teoria parcial e patriarcal esses maus assuntos vão necessariamente ensejar.Assim, os mais brilhantes, e também os mais modestos, generosos e competentes teóricos, algumas vezes, humildemente, se desculpam por serem apenas indivíduos suspeitos, porque eles têm que confessar que eles são "culturalmente posicionados no lado dominante de todos os discursos tradicionais- homem heterossexual, branco, de classe média e acadêmico". 8

"Hard sciences" ou "soft theories": serão estas as altternativas que nos restaram? Não necessariamente, porque nós emprestamos nossos exemplos de territórios imensos, ainda inexplorados, e distantes dos limites das produçōes ocidentais para as quais existe uma velha tradiçáo hermenêutica. Seria bem mais fácil se nós elaborássemos nossa própria teoria dentro da tradição ocidental do teatro de mimesis. A dificuldade (e a vertigem) da análise vem do estranhamento (para nós ocidentais) dos espetáculos analisados e da real impossibilidade de abarcar essa diversidade extrema. Nos últimos dez anos o campo da análise do espetáculo expan- diu-se para todo tipo de performance, isto é, a qualquer ação percebida por um observador em qualquer quadro de referência.

Sintomaticamente, o debate atual não lida mais com epistemologia ou metodologia, mas quase que exclusivamente com a extensão do campo de espetáculos, se deveriam chamarse estudos da performance, etnocenologia, ou teatralidade. Um campo sem nenhum limite que se torna cada vez maior, com o incremento das atividades de jogo e com a metaforização: a noção de teatralidade é pois usada para todos os tipos de práticas: rituais, açōes da vida cotidiana, artes plásticas, urbanismo, paisagismo, etc. A noção de teatralidade é utilizada tão freqüentemente, com todos os tipos de açóes culturais, que se torna somente metafórica, recusando-se a qualquer abordagem analítica, ignorando os objetos descritos, ou impondo sobre eles uma designação muito banal. Esse é o caso, por exemplo, com as metáforas que a "land art" (arte da paisagem) empresta das noçóes de teatralidade, mise-en-scène, espetáculo. Todas as cenas, da cena que você faz para a sua esposa, até as paisagens norte-americanas re-arranjadas pela "land art", são chamadas "teatrais", pelo menos no olhar de um observador, mesmo que seja um potencial. Eles são espetáculos feitos por homens e mulheres entretendo-se com práticas humanas que se lhe oferecem como um show. Mas se todos os territórios do espetacular foram requisitados e colocados sob uma grade, os meios de análise não foram dados, as questóes metodológicas não foram perguntadas e as questôes epistemológicas se aprofundaram. Tem-se a dificuldade e a recusa à escolha de uma dada metodologia para a etnocenologia ou para os estudos de performance sob o pretexto que "construindo uma ciência puramente descritiva ou

7 Gayle Austin. "Creating a feminist theatre environment: the feminist theory play". In: Studies in Literary Imagination, vol. XXIV, n. 2, 1991, p. 54

8 Marvin Carlson. Theories of the Theatre. Ithaca, Cornell University Press, 1993, p. 40. 
simplesmente interpretativa reforçaria-se a ilusão monomórfica” . ${ }^{9}$ E ainda, a etnocenologia, também procura " combinar áreas discretas de estudo (de uma forma interdisciplinar) combinando uma análise interna que respeita os critérios da cultura estudada, e análise externa, baseada em noçóes científicas e métodos usados correntemente". ${ }^{10}$ Está consciente "que é fundamentalmente necessário abarcar quantos pontos de vistas sejam possíveis, não para justapôlos, mas com a intenção de elaborar complexos sistemas para a compreensão dos fenômenos". ${ }^{11}$ Contudo, não se confia nos métodos de análise das performances ocidentais, e não se sabe como lidar com a complexidade das formas extra-européias. Se a etnocenologia, ou a análise intercultural, ou os estudos da performance querem realmente tornar-se uma "nova disciplina",12 eles tem que inventar, gostem disso ou não, uma metodologia para descrever a interpretar os objetos de análise. Daí a importância da tradição hermenêutica intracultural (que não é apenas ocidental) para os estudos interculturais. Em nossa pressa de não esquecer nada, negligenciamos a busca de como as análises de espetáculos deveriam operar com objetos estrangeiros e interculturais.

Agora essas renúncias a uma análise metódica de considerações sociais, econômicas ou estéticas, são também as renúncias ao nosso pró- prio tempo que já não quer ouvir nada de nosso passado ou futuro, um tempo narcisisticamente preocupado com sua maldita atualidade. Só deseja-se o desfrute de tudo, e imediatamente. $\mathrm{E}$, ainda, as mise-em-scènes auto-reflexivas da teoria à maneira do "Nouveau Roman" nos anos setenta, ou das performances nos anos oitenta, não se adaptam mais à nossa experiência contemporânea do mundo, nem às teorias que, se supõe, pudessem explicá-lo. Eles não produzem uma nova compreensão e conhecimento do objeto analisado e do método de análise, mas, no máximo, um elegante, mesmo que estéril, jogo.

Mas voltemos um pouco à tradição intracultural: Será possível encontrar um equilíbrio e uma sintonia fina entre prática e teoria, quando se define um programa de estudos teatrais? E essa sintonia fina, seria utilizável em experiência interculturais?

Tornou-se difícil fazer proposiçóes para os estudos teatrais. Sem correr o risco de ser imediatamente apanhado e desconstruído pelas políticas de assuntos universitários, ou ser reprovado por ter favorecido somente a prática, ou negligenciado a teoria. O mapa dos estudos teatrais e de seus nichos estruturais é muito difícil nos dias de hoje porque está borrado por demandas contraditórias, e porque torna-se problemático traçar um programa de ensino que se localize no emaranhado das práticas e das teorias.

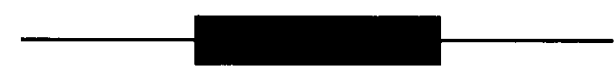

9 Jean-Marie Pradier. "Ethoscénologie. La profounder des emergences". In: Internationale de L'Imaginaire, n. 3. "La scène et la terre. Question d"ethoscénologie". Babel, Maison de Cultture du Monde, p. 20.

Ibid., p. 20.

11 Ibid., p. 21-2,

12 Ibid., p. 41. 